\title{
Poema-partitura e poéticas vocais
}

\author{
Annita Costa Malufe \\ $\mathrm{USP}^{1}$ \\ Silvio Ferraz \\ Unicamp
}

\begin{abstract}
Resumo
Marco de uma certa contemporaneidade poética, o poema-partitura Un coup de dés (Mallarmé) pode ser apontado como um caso exemplar dentre caminhos que surgirão em seguida, na poesia do século $\mathrm{XX}$, propondo uma leitura ligada ao potencial sonoro da palavra e seu desenrolar no tempo. Uma aproximação entre poesia e música, ou um caminho para a emergência de uma musicalidade da fala na escrita. Há uma performance que se põe em jogo na leitura, da qual o próprio sentido do poema passa a depender. Haveria aí um tipo específico de "poéticas vocais", empenhadas no fluxo da palavra falada, buscando tornar palpável e sensível, mesmo na leitura silenciosa de cada leitor, a presença da voz que fala, grita, murmura, gagueja ou balbucia. $\mathrm{O}$ artigo apresenta algumas poéticas vocais, que trabalhariam neste sentido - casos como os de Samuel Beckett, Ghérasim Luca e, mais recentemente, Christophe Tarkos. O objetivo é explorar os potenciais de contágio na poesia escrita pela vocalidade da leitura em simpatia com percurso semelhante dado na música do século XX: da nota musical abstrata à imersão na concretude do som.
\end{abstract}

Palavras-chave: Poesia; performance; partitura; vocalidade; imersão.

\section{Resumé}

Indice d'une certaine contemporanéité poétique, le poème-partition Un coup de dés (Mallarmé) ouvrirait plusieurs chemins à la poésie à partir du XXème siècle dans le sens d'une lecture plus attachée à la puissance sonore de la parole et son déroulement dans le temps. Une approximation entre poésie et musique, ou même un voie vers l'émergence d'une musicalité de la parole dans l'écrit. Il y a une performance qui se met en jeu dans la lecture, à laquelle le sens même du poème vient dépendre. On observe là un type spécifique de "poétiques vocales ", dédiées au flux de la parole parlée, dans le projet de rendre sensible la présence de la voix qui parle, crie, murmure, bégaye, balbutie - même dans une lecture silencieuse. Cet article présente certaines poétiques vocales qui travaillerons dans se sens - celles de Samuel Beckett, Ghérasim Luca e, plus récemment, Christophe Tarkos -, en explorant les puissances de contamination dans la poésie écrite par la vocalité de la lecture, se mettent en accord au parcours du changement de paradigme de la musique au XXème Siècle: de la note musicale abstraite à l'immersion dans le son concret.

Mots-clés: Poésie; performance; partition; vocalité; immersion.
1. O presente trabalho foi realizado com apoio do CNPq, Conselho Nacional de Desenvolvimento Científico e Tecnológico - Brasil. 
Penser la Musique aujourd'hui, 1963; XENAKIS, Iannis.

Musique et Architecture, 1971; MESSIAEN, O. Techniques de mon langage musical, 1940; BOUCOURECHLIEV, Andé. Le Langage musical, 1993.

3. MURAT, Michel. Le Coup de dés de Mallarmé, 2005, p. 160. Sobre este tema, ver neste livro em especial o capítulo intitulado justamente "Une partition" ["Uma partitura"].
Poema emblemático da contemporaneidade em poesia, Un coup de dés [Um lance de dados] (1897) de Mallarmé é frequentemente evocado quando se trata de abordar questões relativas à dimensão visual ou espacial da poesia. Foi esse aspecto ligado à visualidade que, entre nós, acabou de certo modo privilegiado a partir da leitura dos poetas concretos, Haroldo e Augusto de Campos e Décio Pignatari, e sua ênfase na ideia de estrutura. Ainda que reconhecendo a relação declarada por Mallarmé de seu poema com a música de concerto, a leitura dos concretistas contribuiu para uma ênfase naquilo que, no poema, sugere a deslinearização do discurso e sua retirada do fluxo temporal. O poema "tipográfico e cosmogônico" de Mallarmé tornava-se aí um precursor da composição poética estrutural, que viria a ser usada na música, no dodecafonismo de Arnold Schöenberg ou no serialismo de Pierre Boulez e Karlheinz Stockhausen. Para eles, Mallarmé seria, assim, o precursor de um modo de composição, tanto na poesia quanto na música, baseado em uma estrutura abstrata preexistente, ideal, e, portanto, retirada do desenrolar do tempo.

Para os concretos, a relação com a música proposta por Mallarmé se dá, sobretudo, no que concerne à identificação de tema e motivos secundários e adjacentes, ou seja, ela refere-se a uma relação de tipo estrutural: o poeta teria transposto para a poesia uma estrutura própria à música e que, justamente por ser uma estrutura, é uma rede de relações que preexiste à sua encarnação em um material sonoro (ou verbal). Uma rede abstrata, portanto, como numa relação de natureza matemática. Da ligação entre essas artes, portanto, dando-se a partir de uma estrutura abstrata comum, resulta-nos uma ideia de espacialização do tempo - aspecto de fato privilegiado por algumas vanguardas musicais a partir do pós-guerra ${ }^{2}$. Assim, espalhar as palavras pela página, romper a linearidade das linhas do papel, e das linhas do verso, equivaleria nesta leitura a ocupar visual e espacialmente a página. Equivaleria, portanto, a espacializar o fluxo temporal da palavra, criando um poema que privilegia a dimensão visual. Como se o fluxo temporal, diacrônico, fosse captado e fotografado, resultando em uma imagem sincrônica, de coexistência de múltiplos tempos em um espaço ideal, abstraído de sua matéria empírica. É a partir de tal leitura que nos acostumamos, na recepção brasileira, a ler no poema de Mallarmé, sobretudo, um trabalho com a visualidade do texto.

No entanto, como diz Michel Murat em seu livro dedicado ao poema de Mallarmé: "O Un coup de dés se produz à escuta ao mesmo tempo que à visão, como uma tempestade com relâmpago e trovão"3. E esta simultaneidade entre os sen- 
tidos encontra uma boa imagem na noção de partitura, tal como é salientada por Mallarmé ao apresentar seu projeto no prefácio ao poema. Como Murat também destaca, é a noção de partitura que efetua a articulação entre a dimensão visual do poema e sua dimensão sonora, inaugurando (ou explicitando) na poesia uma relação interessante entre esses dois sentidos - a visão e a audição. Ou seja, não se trata somente de uma relação estrutural, e abstrata, que existiria em sua concepção do poema enquanto uma "subdivisão prismática da ideia", por exemplo. Trata-se, sobretudo, de uma notação. Se, por um lado, Un coup de dés pode ser lido como a representação do próprio pensamento se fazendo, nessas subdivisões da Ideia - conforme o próprio fecho do poema: "Todo pensamento emite um Lance de Dados"4 - por outro, valeria destacar a ênfase na sugestão rítmica contida no desenrolar do poema. Algo que parece sugerir, desde o projeto de Mallarmé, uma vivência corporal do poema, uma inclusão da experiência física da escuta de uma música - mais diacrônica do que sincrônica, portanto.

No prefácio a Un coup de dés, a ênfase de Mallarmé é dada no ato da leitura, sugerindo que o poema seja lido como uma partitura. A espacialização das palavras na página e o jogo com a tipografia, a partir da variação de tamanhos, o uso do itálico, o negrito ou as caixas altas, teriam como função guiar a leitura, em especial aquela que fosse feita em voz alta:

Ajunte-se que deste emprego a nu do pensamento com retrações, prolongamentos, fugas, ou seu desenho mesmo, resulta, para quem queira ler em voz alta, uma partitura. A diferença dos caracteres tipográficos entre o motivo preponderante, um secundário e outros adjacentes, dita sua importância à emissão oral e a disposição em pauta, média, no alto, embaixo da página, notará o subir ou descer da entonação ${ }^{5}$.

Era, portanto, a execução sonora que era levada em conta pelo poeta na disposição gráfica inusitada de seu poema, na dinâmica criada entre as tipologias e os brancos da página, fator bastante explorado, por exemplo, na leitura de Michel Murat. Com o que podemos até nos perguntar o quanto a espacialização de fato romperia por inteiro com qualquer linearidade, uma vez que ela pressupõe uma linha sonora: uma continuidade, mesmo que interrompida, da voz que lê e segue a partitura proposta na escrita. Ou seja, ela conta com uma "linha" da leitura, e não se restringe necessariamente a uma leitura espacializada e simultânea - como seria, por exemplo, aquela da visão que passeia, em idas e vindas, pela imagem de um quadro ou de um poema estritamente visual.

Ao falar de Un coup de dés, Octavio Paz salienta justamente a comparação feita por Mallarmé entre a distribuição
4. Na tradução de Haroldo de Campos de Um lance de dados, do verso "Toute pensée émet un Coup de Dés”. In: CAMPOS, Augusto de; PIGNATARI, Décio e CAMPOS, Haroldo de. Mallarmé, 1974, p. 149-173.

5. Ibidem, p. 151. 
6. PAZ, Octavio. Signos em

Rotação, 1996, p. 27. do poema na página e a ideia de partitura e diz: "Não creio no fim da escritura; creio que cada vez mais o poema tenderá a ser uma partitura. A poesia voltará a ser palavra pronunciada" 6 . $\mathrm{O}$ poema de Mallarmé, para Paz, seria um marco entre as poéticas moderna e contemporânea; abriria uma nova tendência que, para ele, refere-se justamente à sugestão de um texto que é mais do que escrita: é também voz e execução, performance. Um retorno às fontes orais da poesia. $\mathrm{O}$ aspecto sonoro sobressai aqui ao visual, ou submete este àquele. Assim, no caso de $U_{n}$ coup de dés, ao mesmo tempo em que o poema se espacializa, descobre o espaço da página, ele está de fato propondo uma superação da página. Ele sugere uma saída do livro, uma expansão para fora do silêncio da página, incentivando a leitura em voz alta e o paralelo, como diz ele, com "a música de concerto". Como pede Mallarmé, trata-se de uma partitura, um poema e sua rubrica de realização temporal.

Esta vontade de expansão, de romper com os limites da página e sua mudez é o que vai caracterizar diversos experimentos que atravessaram o século $\mathrm{XX}$ nos cruzamentos entre poesia, música e performance. Nas primeiras vanguardas, em especial futurismo e dadaísmo, os poemas fonéticos de Hugo Ball e Kurt Schwitters (como no seu conhecido "Ursonate", 1922), compostos exclusivamente por sons, palavras inventadas. Nas vanguardas do pós-guerra, anos 50 , já em diálogo com o que será a música eletroacústica, as experimentações vocais e colagens. Em alguns poetas vindos do surrealismo, como Brion Gysin (1916-1986), François Dufrêne (1930-1982) e Henry Chopin (1922-2008), um dos pioneiros no uso de gravadores para leitura e criação de poemas com efeitos de microfones, reverberações e explorações da voz, ou Ghérasim Luca (19131994), também saído dos surrealistas. Bernard Heidsieck (1928, ainda vivo), na sua ideia de "poesia-ação" e na composição de seus "poemas-partituras" (poèmes-partitions). Nas performances vocais do grupo Fluxos e nas performances e escritos do compositor John Cage, como realizada em seu Silence. Até nos poetas e músicos da segunda metade do século, já com uma tecnologia eletroacústica mais avançada - como é o caso de obras como Visage e Stimmung de Luciano Berio e Karlheinz Stockhausen, ou mais recentemente no trabalho vocal do compositor e poeta grego, radicado na França, Georges Aperghis. $\mathrm{Ou}$, ainda, naqueles que se utilizam da tecnologia apenas para registro, gravação de sua voz lendo poemas, sem o uso de efeitos eletroacústicos, como no caso de Christophe Tarkos (19632004), que era bastante afeito às performances públicas de seus poemas.

Em todos esses casos, o que se vê são diferentes propostas ao longo do século XX no sentido de dar materialidade, espacialidade, sensorialidade, tatilidade, ou ainda, corporeidade às 
palavras. No domínio da poesia, o caso mais explícito é o do poeta Bernard Heidsieck com seus poemas-partitura, que funcionam de fato como uma partitura musical em que a disposição no papel atua como um roteiro de indicações de leitura em voz alta: ritmo, durações, velocidades, mudanças de tom... 7. Heidsieck define-se como autor de uma "audio-escrita" ou uma "auditura", em lugar de uma escrita ou escritura. Propondo com isto que o leitor, a ler o seu poema, na verdade "ouve" o texto: é imerso em uma situação de escuta. O leitor torna-se assim mais ouvinte do que leitor. Aquilo que será a sua interpretação, sua execução, por um futuro leitor, intérprete do poema, constitui a própria forma e estrutura do poema, em geral escrito com indicações visuais que sugerem suas vocalizações.

Tal qual realizou, por exemplo, John Cage ao longo de seu livro Silence, a visualidade gráfica do texto traz indicações diversas de leitura: os gestos, entonações, dinâmicas, pausas, retomadas. Contém assim os índices de vocalidade ou oralidade - se quisermos nos valer da expressão de Paul Zumthor ${ }^{8}$, ao se referir à lírica trovadoresca medieval, destinada à performance pública. É pela sua funcionalidade enquanto partitura, enquanto tentativa de escrever os gestos de leitura do poema que será determinada a sua visualidade na página, tal como na notação de Un coup de dés: o corpo do poema constitui-se e inclui em sua forma a sua própria execução oral, sua vocalização. Tal como nas notações da poesia medieval, na qual o texto era apenas uma espécie de intermediário, uma partitura, a ser executada publicamente, o poema nasce marcado por esses índices, e, portanto, já levando em conta o momento e o ato de execução da leitura - ou seja: ela internaliza essa performance em seus componentes.

Em Cage, experimentações de escrita fizeram com que incluísse em seus textos indicações de duração de pausa e tempo de leitura (por exemplo, em “ 45 ' for a speaker”), espaços de pausas entre palavras (em "Lecture on Nothing”), espaços entre blocos de texto ("Erik Satie"), escrita em colunas e uso de negrito ("where are we going? and what are we doing?"), uso de linhas para separar colunas com espaçamentos diferentes entre palavras ("Composition as a process"). Tais estratégias utilizadas nos textos reunidos no livro Silence, escritos e apresentados entre 1939 e 1961, ganharam mais força ainda em seu livro $M$, com textos escritos entre 1967 e 1972. Em $M$, o uso de "letraset", brincando com a visualidade do poema, buscou dar ainda mais ênfase na leitura, no uso da escrita enquanto guia de performance. Letras pequenas, grandes ou minúsculas, mudanças de tipologia, o uso de espaços, o "amontoamento" de letras e palavras, formando desenhos - em algo que pode nos lembrar os Calligrammes de Apollinaire - sinalizavam modos diferentes, mas não determinados de realização, sobretudo no
7. BOBILLOT, Jean-Pierre. Bernard Heidsieck, poésie action, 1996, p. 37.

8. Ao estudar poemas orais da tradição medieval, Zumthor fala em "índices de oralidade" ao se referir a indicações presentes nos manuscritos medievais que remeteriam às execuções orais desses poemas - os índices eram, por exemplo, verbos que se referiam à oralidade. Esses textos eram as primeiras notações. ZUMTHOR, Paul. La Lettre et la voix, 1987, p. 42. 
9. Cf. CAGE, John. Silence, 1973; CAGE, John. M, 1974.

10. CAGE, John. M, 1974, p. 162; CAGE, John. Silence, 1973, p. 154.

11. BOBILLOT, Jean-Pierre. Bernard Heidsieck, poésie action, 1996, p. 40. conjunto que denominou Mesostics ("Re and Not Re Marcel Duchamp"; "Re Merce Cunningham"; "Re and not Re Mark Tobey”). No mesmo livro, outras experimentações se dão neste sentido. A escrita do texto "Mureau", por exemplo, sem pontuação, com palavras amalgamas, mudanças de tipos e inserção de caixas altas no meio de algumas palavras, cria um texto em fluxo contínuo com algumas marcas que podem ser de mudança de entonação, ritmo ou breves pausas ou truncamentos na leitura'.

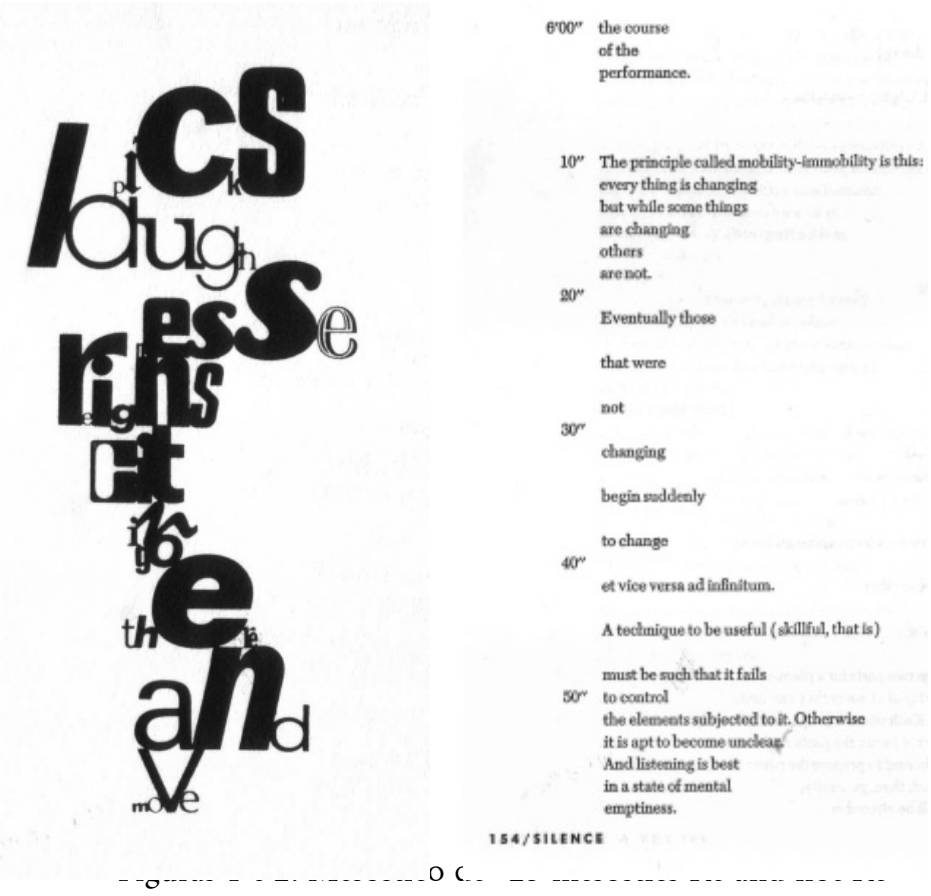

Mark Tovey" e passagem entre o sexto e sétimo minuto da partitura de leitura de “45' for a speaker". A primeira, uma partitura visual para voz ou qualquer instrumento, ou apenas para ser vista. A segunda traz indicações de velocidade de leitura e duração de pausas através de marcação de segundos ${ }^{10}$.

Muito próxima a esta proposta de Cage estava a de Heidsieck em seu Poème-partition V, de 1956, em homenagem ao compositor Edgar Varèse. Conforme Heidsieck, o "V" do título remeteria ao mesmo tempo ao nome do compositor e a vitesse, rapidez ou aceleração do próprio poema. Poema-veloz, poème-vite, no sentido de que: "a velocidade de dicção, com todos seus efeitos, mais ou menos manifestos, mais ou menos específicos, é parte integrante do texto - está inscrita, explicitamente, na própria forma do enunciado", diz o poeta ${ }^{11}$. Assim concebido, o poema sonoro abole a dicotomia tradicional texto versus interpretação ou objetividade do texto versus subjetividade interpretativa. $\mathrm{O}$ poema é veloz em si mesmo; este traço, que pode ser o da leitura - ler rapidamente, ler de modo acelerado -, estaria contido no próprio poema, sendo 
um traço constitutivo do texto (e não algo contingente, que dependeria apenas do intérprete). Quase como Cage, que em “45' for a speaker”, determina em segundos o tempo de leitura de cada linha, Heidsieck também especifica para cada poema o seu tempo total de leitura em minutos. Para reforçar ainda mais tal aspecto temporal, ou gestual, contido em seus poemas, se valia no domínio próprio da escrita das frases, de frases prontas, de expressões orais, e escrita polifônica a duas vozes, como em "Canal Street, planche 42"12.

A partir da noção de partitura encaminhamo-nos, assim, para duas tendências que parecem conversar entre si: por um lado, a sugestão de que o poema se dirige a uma execução, ele é este intermediário (Zumthor) de uma performance maior, que o extrapola e que acontecerá no ato de leitura (que pode ser um ato público, gravado ou não, ou gravado, público ou não); por outro, tem-se o fato de que o poema, como nos casos de Mallarmé, Heidsieck e Cage, traz em si as marcas que regerão essa performance - ou seja, ele internaliza essa voz, a incorpora. Dois movimentos, portanto: um de sair da página, ir para a voz no sentido empírico do termo - em gravações ou performances coletivas - e, simultaneamente, outro movimento de retorno à página, mas aí já internalizando na escrita esses movimentos de saída. Como se o poema assimilasse em seu próprio corpo de escrito a experiência do palco, da voz alta, do som audível e internalizasse sua própria performance. Como diz Heidsieck, é o poema que é "veloz" - e consequentemente sugere uma leitura acelerada - a rapidez é parte dele, o constitui, e não pertence apenas à contingência do momento em que for lido.

\section{Performance}

Tal qual no projeto de Un coup de dés de Mallarmé, pode-se destacar ainda a sugestão de que o poema escrito como partitura ressurgiria a cada leitura, a cada performance, como que uma primeira vez. Como um lance de dados, se faria assim a cada vez de modo único e irrepetível. Ou seja, o poema é uma partitura e, tal como acontece com uma peça musical, sua execução é algo único, que acontecerá sempre de um novo modo, no tempo inédito de cada leitura. Mallarmé nos põe, assim, frente à importância da performance no poema. Neste poema de 1897 a ideia da leitura enquanto execução nos aproxima daquela de performance que Paul Zumthor destacava na poesia oral medieval. Podemos então estender este conceito de performance para todo tipo de leitura - não somente aque-
12. HEIDSIECK, Bernard.

"Canal Street 200, planche 42".

In: Canal Street, 2001, p. 52. 
13. ZUMTHOR, Paul.

Performance, recepção, leitura, 2000, p. 41.

14. Ibidem.

15. BOBILLOT, Jean-Pierre. Bernard Heidsieck, poésie action, 1996, p. 116. las executadas presencialmente, por intermédio de um ator ou aquelas do próprio autor lendo seus poemas em público, mas também pela simples presença de um leitor e do texto.

Como salienta Zumthor, o que define a experiência poética é "uma implicação forte do corpo", ${ }^{13}$ o que fará parte de qualquer leitura ou escuta; seja ela em presença (empírica) ou não de um outro corpo para além do nosso e para além do corpo do texto: "Que um texto seja reconhecido por poético (literário) ou não depende do sentimento que nosso corpo tem". ${ }^{14} \mathrm{E}$ este reconhecimento pode acontecer na escrita, independentemente de estarmos diante de alguém que profere o texto em voz alta. A performance implica portanto em dois traços típicos da experiência poética: a presença de (ao menos) um corpo; a confluência de uma rede de encontros, um cruzamento, dando-se de modo irrepetível, em um "tempo real” de execução, na presença deste corpo. Ou seja, toda leitura pode ser vista assim, como a execução única e em tempo real de um texto. Execução esta que se dá a partir de um corpo, ao menos, que entra em relação com o corpo do texto.

Muito próximo a essas ideias, Heidsieck diz interessar-lhe o poema como presença, que se põe de corpo presente ao leitor ou, como propõe, ao ouvinte. $\mathrm{O}$ ato poético, já não recorrendo à mímeses, torna-se uma presença em si, enquanto corpo que interage com outros, implicando em uma imersão na objetividade das coisas ${ }^{15}$. Tal é a sua proposta da "poesia-ação": um poema que aja diretamente no e com o mundo, que faça o poema sair da passividade do escrito para entrar no mundo, assumindo os riscos da comunicação, da atuação, da performance. Este é o projeto mais amplo que engloba os seus poemas-partituras, bem como outros poemas dos quais encontramos gravações realizadas pelo próprio poeta.

Como vimos, embora o conceito de partitura compreenda uma liberdade - a ideia de que o leitor deverá executar o poema a partir de sua voz, seu corpo, seus modos particulares de ler -, ele ao mesmo tempo implica uma restrição - na ideia de que o texto já traz no seu corpo de escrito, as velocidades, os modos de acelerar ou ralentar, os momentos de pausa, calma, hesitação ou exaltação, tensão ou relaxamento que marcarão as leituras porvir. Ele apresenta um campo ao mesmo tempo infinito de possibilidades de leitura (como prever a voz que lerá o poema?), porém, um campo limitado pelas linhas reais e efetivas do poema. O poema é um roteiro de leitura e escuta, portanto, e a liberdade de execução se dará dentro dessas margens, que são por fim os próprios limites e contornos que conformam o texto. E até mesmo a leitura realizada pelo poeta autor será apenas uma das realizações do texto, não existindo uma "execução ideal” do poema. 
Mas não devemos também evitar a leitura do próprio poeta. Desde o advento dos dispositivos de registros fonográficos não há como fugir à existência de gravações de poetas, de atores reconhecidos, que de um modo ou outro vieram conviver lado a lado com o poema impresso. Se estas não precisam ser tomadas como restritivas dos modos de interpretação do poema partitura, elas, no entanto, podem indicar caminhos pelos quais podemos aliar a própria voz do poeta, seus gestos de fala, suas sonoridades privilegiadas, à gênese de suas escritas.

As gravações extremamente performáticas do poeta romeno radicado na França Ghérasim Luca (1913-1994) sugerem o modo como criava seus poemas, moldados por uma voz, por uma onda vocal. Como ele mesmo afirma, na introdução a um recital: o poema "toma a forma da onda que o pôs em funcionamento". "Eu me oralizo", diz ele. ${ }^{16}$ É todo o poeta que se oraliza, ou se vocaliza, no poema. É claro que ao termos escutado o poeta lendo, a sua performance, dificilmente conseguimos nos desfazer dela. No caso específico de Ghérasim, talvez seja difícil decidir se é o poema que sugere uma velocidade acelerada ou se esta teria sido imposta pela aceleração da leitura que ele realiza, com seu excesso de ofegância, seu modo afoito de ler, repleto de humor e irreverência, intensificados por seu sotaque romeno, ao ler os poemas em francês.

Um bom exemplo é seu poema "Passionnément", lido em velocidade crescente, sôfrega, afoita. Será que ao lermos, sozinhos, o poema, em silêncio, e sem termos antes a escuta da voz de Ghérasim, sentimos o ritmo progressivamente acelerado, culminando em um grito ao final, na exclamação "Je t'aime passionnément”? Vejamos o início do longo poema (do qual mantemos a diagramação original, centralizada):
16. "Je parcours aujourd'hui une étendue où le vacarme et le silence s'entrechoquent - centre choc -, où le poème prend la forme de l'onde qui l'a mis en marche. Mieux, le poème s'éclipse devant ses conséquences. En d'autres termes : je m'oralise." LUCA, Héros-limite, suivi de La Chant de la carpe et de Paralipomènes, 2001, p. XII-XIII.

PASSIONNÉMENT

pas pas paspaspas pas

pasppas ppas pas paspas

le pas pas le faux pas le pas

paspaspas le pas le mau

le mauve le mauvais pas

paspas pas le pas le papa

le mauvais papa le mauve le pas

paspas passe paspaspasse

passe passe il passe il pas pas

il passe le pas du pas du pape

du pape sur le pape du pas du passe

passepasse passi le sur le

le pas le passi passi passi pissez sur

le pape sur papa sur le sur la sur

la pipe du papa du pape pissez en masse 
la basse passi passepassi la passio passiobasson le bas le pas passion le basson et et pas le basso do pas

paspas do passe passiopassion do ne do ne domi ne passi ne dominez pas ne dominez pas vos passions passives ne ne domino vos passio vos vos ssis vos passio ne dodo vos vos dominos d'or c'est domdommage do dodor do pas pas ne domi pas paspasse passio vos pas ne do ne do ne dominez pas $(. . .)^{17}$

Em sua leitura, Ghérasim Luca torna sensível em sua voz, ao executar o poema, esta aflição em tentar dizer, em se esforçar por dizer, aflição que vai em um crescendo ao longo do poema. Há o esforço de um nascimento, como se o dizer fosse nascendo junto com o dito, juntamente com as palavras - ou como se as palavras fossem nascendo deste esforço repetitivo, reiterativo. O que vai ser dito, em termos de significado, não é tão relevante - é até algo trivial, toda esta construção vai levar à frase final, "Je t'aime passionnément", que nada teria de muita novidade poética ou inventiva. Esta expressão final é uma expressão-limite, que parece ir sendo construída aos poucos, nos tropeços e aflições de uma fala repetitiva, tateante - ou "gaga" se quisermos seguir a definição cavada por Deleuze em seu ensaio em Crítica e clínica. O que vale é o modo que ele chega a ela, e o sentido do poema está muito mais no leitor/ouvinte acompanhar o percurso que vai dar nesta frase, os desvios, os tropeços, os esforços dessa voz que vai tentando moldar essa frase última, fazendo-a vir como num sopro final - que Deleuze definirá como um sopro no limite do grito.

Porém, mesmo sem termos por referência a gravação da leitura de Ghérasim, esta oralização da gagueira escrita, este gesto de gagueira, nós a conhecemos como resultado de uma tentativa de fala rápida, que tropeça. Como se o poeta conseguisse escrever o tempo de leitura através de seu tema, deste tentar dizer uma frase extremamente curta: “je t'aîme passionnément”. Como se este curto espaço de tempo preenchido pela frase tivesse de corresponder ao tempo de leitura das linhas do poema, como que as de monossílabas reiteradas e encavaladas pedissem para ser lidas tão rápido quanto a brevidade da frase final, fazendo as correr. Ghérasim escreve assim o tempo de leitura sem a necessidade de rubrica, tal qual vimos em Cage e Heidsieck. 
Nos jogos de vai-e-vem das sílabas reiteradas, no surgimento lento de novos fonemas e palavras, há como que uma língua própria que se cria, uma língua que nasce a partir de sua vocalidade, de sua vocalização ${ }^{18}$. E nós, angustiadamente, seus leitores e/ou ouvintes, vamos acompanhando esta voz que faz nascer uma língua, vamos vivendo, em tempo real, o processo de fazimento desta língua, a partir da voz. É esta criação de uma língua que Gilles Deleuze sugere em sua leitura do poema de Ghérasim, criando a partir daí o conceito de gagueira criadora. Para o que nos interessa, sublinhemos o quanto este conceito traz com ele uma característica própria da fala, ou própria do oral, do vocal. Dizer que alguém é "gago" da escrita é levar à escrita algo que não costuma ser dela, pois quando se diz de alguém que é gago, se diz de sua fala e não de sua escrita. O que interessa, portanto, é este modo de fazer as palavras escritas adquirirem uma potência de fala - e ao fazer isto o que se criaria é um abalo muito maior, infiltrado na própria língua. Ao lado de Ghérasim, Gilles Deleuze observa que a gagueira também estaria presente em outros autores, como Samuel Beckett, que constroem sua língua própria, seu estilo, calcados em um afeto que é próprio da voz proferida, da voz que fala, que tem som. Um estilo calcado em afetos vocais. Estilo invadido pelo som e por sua temporalidade. De modo que podemos inferir que a vocalidade é um elemento ou um afeto que pertence à própria escrita do poema, a seus movimentos e contorções internas, independentemente de ser oralizado ou não em voz alta.

O fato é que a leitura expressiva e singular de Ghérasim possui a qualidade de intensificar traços presentes no poema escrito: esse processo de formação da frase final culminante, percurso a que o poema nos expõe; o esforço de tentar pronunciar; o humor, presente na escolha das palavras e no modo de repetir; a brincadeira excessiva com as repetições, trazendo o efeito de uma gagueira inusitada; a velocidade de leitura que ao final se acelera, pelo fato de trazer por fim, após um longo caminho de expressões que truncam a leitura, orações que são mais fácil e rapidamente compreensíveis, a partir da oração simples e batida "je t'aime":
18. DELEUZE, Gilles. "Bégayat-11...”. In: Crítique et clinique, 1993, pp. 135-143.

\author{
je je t'aime \\ je t'aime je t'ai je \\ t'aime aime aime je t'aime \\ passionné é aime je \\ t’aime passioném \\ je t'aime \\ passionnément aimante je \\ t'aime je t'aime passionnément \\ je t’ai je t'aime passionné né
}


19. Ibidem.

20. SARRAZAC, Jean-Pierre (org.). Léxico do drama moderno e contemporâneo, 2012, p. 67.

21. Ibidem, p. 68. je t'aime passionné

je t'aime passionnément je t'aime je t'aime passio passionnément ${ }^{19}$

Esta leitura de Ghérasim de seu próprio poema torna sensíveis forças que estão internalizadas na própria escrita, muitas delas ligadas justamente à vocalidade, e deve ser vista como uma das leituras infinitamente possíveis dadas no campo de virtualidades do texto. Que ela seja expressiva justamente por fazer aflorar, tornar sensíveis, forças que se encontram no poema, isto é um fato a ser considerado. Contudo, de modo algum descarta que alguém que não conheça a leitura do autor talvez possa efetuar uma performance bastante diferente e nem por isto mais distante ou infiel ao texto (tido neste caso como um suposto original). Ou seja, a performance nos coloca sempre diante de um novo original: ela inaugura um plano de composição novo, que se dá no embate da voz (silenciosa ou não) do leitor com o suporte escrito do texto. O que importa, sobretudo, é que deste encontro um novo plano sempre se dá, sem a nostalgia de um original perdido. Ao se pensar a partir do conceito de performance, quebra-se a lógica do modelo e da cópia.

Ao abordar essa mesma problemática, mas no campo específico do teatro, Jean-Pierre Sarrazac propõe um outro conceito de interpretação teatral não mais calcado no modelo da representação - segundo o qual cada montagem de uma peça seria uma cópia mais ou menos bem executada do texto dramatúrgico enquanto um original jamais alcançável: "convém acabar definitivamente com a cobrança textocentrista de uma representação teatral que não passaria da 'realização' de um texto", $\mathrm{diz}^{20}$. À esta sempre reiterada melancolia da perda do original, Sarrazac propõe a ideia de "devir cênico", a partir do conceito de devir tal como concebido por Gilles Deleuze e Félix Guattari em Mil platôs. Trata-se de pensar em uma potencialidade cênica ou performática inerente ao próprio texto e acionada a cada vez - e de modo único e imprevisível - em cada montagem que se dê no palco. A proposta é que se conceba um corpo a corpo entre texto e palco, entre o texto dramático e outros elementos (cenários, luzes, corpos, vozes, gestos etc.), mas não em um apaziguamento, e sim, antes, numa relação de concorrência e polifonia, de combate não resolvido, entre esses dois planos - diz ele, uma "interface: deslizamento da estrutura-texto e da estrutura-representação uma sobre a outra; sobreposição graças à qual o texto se vê posto em movimento por sua própria teatralidade" 21 , de modo que o devir cênico seria ao mesmo tempo algo infinito porém delimitado pelo texto. Algo que está contido no próprio texto, enquanto suas 
potencialidades infinitas - mas em um campo delimitado que lhe pertencem. O que, nos termos também de Deleuze, chamaríamos como seu campo de virtualidades.

Todo texto, seja ele realizado ou não especificamente para o teatro, assim, pode possuir seu devir-cênico: um campo amplo de virtuais a serem atualizados em realizações cênicas, ou ainda, uma potência de se tornar cena, se tornar espaço-tempo encarnado em corpo e palco, que está contida na própria escrita que empiricamente é muda e desprovida de espaço e tempo. Seguindo essa mesma lógica proposta por Sarrazac, via Deleuze e Guattari, podemos pensar que há poemas que trabalham mais especificamente com o que chamaríamos de um devir-vocal. Uma potência vocal inerente ao poema, investindo a mudez da escrita com vozes a serem escutadas na performance da leitura. Um campo amplo de virtualidades a serem atualizadas em cada leitura, seja ela silenciosa ou em voz alta.

Há uma vocalidade, ou poética vocal, que se encontra nas linhas empiricamente silenciosas de um texto, de um poema. Uma vocalidade que remete a uma performance inerente ao poema, ou a uma leitura que deve ser entendida enquanto performance: execução, corporal e em tempo real, do poema. A leitura como o momento em que há uma presença em jogo - uma presença corporal do poema e do corpo de quem lê. A sugestão é a de que cada leitura seria de fato uma audição inédita, a execução de uma obra, momento em que a obra "acontece", em que ela se faz presente, pela primeira vez, bem como o leitor diante dela - ambos neste ato de performance, presentes, de modo irrepetível.

Esta escrita investida por um devir-vocal ou, poderíamos dizer, que traz as forças de sua performatividade, é o que marca também a dramaturgia, os romances e a poesia de Samuel Beckett. Em especial na sua obra em prosa a partir da década de 60 , encontramos textos que se tornam verdadeiras composições para fluxos de vozes falantes, como se o foco de Beckett fosse justamente a voz que fala, uma musicalidade própria dessa voz. Desde a trilogia romanesca da década de $50^{22}$ este modo de escrita já vinha se apresentando, sendo radicalizado a partir de Comment c'est, de 1961, e se tornando uma marca estilística na chamada segunda trilogia da década de $80^{23}$. Beckett constrói aí uma escrita invadida por afetos vocais, como se trouxesse para a escrita do romance ou da poesia a performance pressuposta na dramaturgia. Nasce aí uma música da fala que se faz na dinâmica de velocidades, entonações, ritmos, oscilações, respirações, hesitações e exaltações, murmúrios e gritos, pausas e retomadas. Algo que Fábio de Souza Andrade definiu justamente como uma "metamorfose do texto em partitura para uma música verbal" que ocorreria na fase final da obra beckettiana ${ }^{24}$.
22. Trata-se dos romances Molloy (1951), Malone morre (1951) e O inominável (1953).

23. Companhia (originalmente em inglês, Company, 1980) e Mal visto mal dito (originalmente em francês, Mal vu mal dit, 1981) e Para frente o pior (originalmente em inglês, Worstward Ho, 1983)

24. A ideia de partitura associase ao que falávamos acerca da relação entre visualidade e escuta, que Andrade define pelo: "casamento dos olhos que leem com a fala, da escrita com a escuta silenciosa", cf. ANDRADE, Fábio de Souza. Samuel Beckett, o silêncio possível, 2001, p. 159. Interessando-nos especialmente aqui esta ideia de uma escuta silenciosa, de "uma escrita que se vale da escuta para se constituir”. Ibidem, p. 160. 
25. BECKETT, Samuel. Como é, 2003, p. 108.
Como Beckett torna necessária a escuta do texto para que ele faça sentido? Como ele aciona nossa escuta na leitura, mesmo que em voz baixa? Em alguns momentos Beckett chega mesmo a inserir no próprio texto as rubricas de sua realização. O leitor é o personagem que ouve o alguém que fala ao seu lado, interlocutor ou não. É o que vemos claramente em Como é quando a entonação é agregada à própria voz que nos fala, como vemos em: "ou melhor nenhuma nenhuma perdida”, neste trecho de Como é:

tantas palavras tantas perdidas uma a cada três duas a cada cinco primeiro o som depois o sentido mesma proporção ou melhor nenhuma nenhuma perdida ouço tudo entendo tudo e vivo outra vez tenho vivido outra vez não digo em cima na luz entre as sombras à procura da sombra eu digo aqui SUA VIDA AQUI em suma minha voz senão nada portanto nada senão minha voz portanto minha voz tantas palavras encadeadas como assim primeiro exemplo ${ }^{25}$.

Notemos o movimento dessas frases encadeadas, dessa espécie de linha contínua, sem pontuação, sem pausas - e que, apesar de ser contínua, traz interrupções, quebras, tropeços. Principalmente em Como é, seguindo um movimento de fluxo de fala iniciado em $O$ inominável, Beckett abre mão completamente da pontuação. O texto não tem parágrafos, nem maiúsculas. Ele é uma sequência de blocos, com tamanhos variáveis. Mesmo lendo sem proferir as palavras em voz alta, o interessante é que há uma voz que pulsa - ou em alguns momentos mais de uma voz -, que parece sair do texto, que se eleva dele, como um vapor, uma onda. E, para que esta voz soe, para que ela seja disparada, é preciso que o leitor embarque neste fluxo vocal e, ainda, que ele mesmo faça as pausas, os acentos, encontre o ritmo da frase, ache o movimento da voz, atualize este movimento no ato de ler. Este ato é, portanto, uma performance. Neste ato, o texto acaba funcionando como uma partitura vocal e a leitura se converte em uma escuta.

Notemos que o personagem desses textos é a própria voz. Neles, já não importa quem fala, qual é o narrador ou os personagens, nem o que é dito - a história narrada, o enredo. O que ganha relevo é o próprio curso da fala, o fluxo da voz, o movimento contínuo de uma voz - como lembrávamos, dinâmica que Beckett parece ter acentuado em O inominável, romance ou anti-romance de uma voz-personagem que mal se encarna em um corpo; em determinado momento, ela se diz proferida por um crânio. No monólogo Not I, de 1975, uma boca - único foco iluminado na escuridão do palco. É como se houvesse uma espécie de autonomização da voz em Beckett. Ela se torna independente, se descola de personagens 
e enredos fixos. E é ela que o leitor ouve narrar acima de tudo o percurso dela mesma, dessa voz em andamento, o percurso de uma vocalidade.

\section{Improviso e imersão rítmica}

Ao falarmos de um leitor que ouve, que está imerso no texto, muda-se o paradigma da própria arte. A partir e Beckett, o leitor não está mais face a um objeto, mas dentro de uma cena sonora que se dá no seu encontro com a obra. Em autores mais recentes, a poesia do francês Christophe Tarkos (1963-2004) impõe-se como um caso expressivo desta poética da imersão. Autor de mais de vinte livros, muitos dos quais nascidos do que ele chamava de improvisações-performances, Tarkos traz uma escrita fortemente atrelada à vocalidade, toda tomada pelo som e o movimento da voz. Mesmo "em silêncio" a leitura de um poema de Tarkos é conduzida pelas constantes circunvoluções vocais que colocam em foco o percurso rítmico dessa voz, suas espirais, seus gestos obsessivos, sua música e sua forma de fluxo contínuo quase ininterrupto. É das circunvoluções, como se o texto girasse no mesmo lugar, que nasce a experiência de imersão. O tempo de leitura fica como que parado nas reiterações ou nas frases que não se completam, que não cumprem seus ciclos, suspende-se o tempo e abre-se o espaço no qual o leitor mergulha.

Novamente é com a música que a escrita dialoga. O tempo suspenso pela reiteração na música dos minimalistas como Steve Reich (1936-), Phillip Glass (1937-) e John Adams (1947). Ou ainda o tempo suspenso pelo seu esgotamento, como em Morton Feldman (1926-1987). Não à toa temos a proximidade entre Beckett e o compositor norte-americano Morton Feldman (1926-1987), com quem escreveu diversos trabalhos em "parceria": a ópera Neither sobre "libreto" encomendado a Beckett; a composição da peça radiofônica Words and music, e a composição de For Samuel Beckett (1986) em homenagem ao escritor. Um dos principais expoentes da chamada música minimalista norte-americana, Feldman ia além de pautar sua escrita na reiteração de padrões melódicos ou sonoros, como os outros minimalistas, trabalhando sobretudo na dilatação do tempo em suas composições, como em seu String Quartet $\mathrm{n}^{\mathrm{O}} 2$, que dura entre seis e sete horas. Dá-se assim esta experiência imersiva, devido tanto à repetição obstinada quanto ao estiramento do tempo inaugurarem outra experiência espaço temporal. Trazem assim para a música, e consequentemente para a arte, o tempo da eternidade, bastante distinto daquele 
26. TARKOS, Christophe.

Caisses, 1998, p. 25. A

diagramação aqui segue aquela

do livro de Tarkos, em que todos os poemas são dispostos na forma de quadrados, de diferentes tamanhos. dos pequenos ciclos medidos e fechados da música tradicional e da sintaxe da linguagem culta.

Esta proposta de um tempo alargado pelas reiterações obstinadas e prolongadas nos escritos de Beckett ganha nova força na escrita de Tarkos. Em seus textos, mais próximos a poemas-em-prosa, o poeta francês retoma o percurso da prosa poética da última fase do autor irlandês, intensificando traços como reiterações, repetições de palavras, de frases inteiras ou expressões, permutações de longa duração e frases incompletas. Entrar na poética vocal de Tarkos pode ser muitas vezes uma experiência de imersão em um outro espaço-tempo, criado neste ambiente de palavras em excesso, trazidas por linhas vocais ao mesmo tempo titubeantes e obsessivas:

Quel est le flux, quel est le flux qui rencontre un obstacle, quel est ce flux, le flux rencontre un obstacle, quel est ce flux qui rencontre un obstacle le flux rencontre plus d'un obstacle, le flux a vu un obstacle par l'obstacle duquel le flux a vu l'obstacle, le flux a voulu aller vers l'obstacle qu'il a vu, voilà un flux qui vient à la rencontre d'un obstacle, les flux viennent à leur rencontre, l'obstacle allait vers les flux, des flux ont vu plus d'un obstacle, quel est le flux, le flux va rencontrer un obstacle qui rencontre des flux, des flux viennent à la rencontre d'un obstacle, l'obstacle attend de voir venir le flux, les flux vont à la rencontre d'obstacles, les flux passent à travers les obstacles, quel est le flux, le flux rencontre des obstacles, le flux attend de rencontrer un obstacle, de nombreux obstacles sont dans les flux, les obstacles arrivent dans le flux, quel est le flux, un flux rencontre un obstacle lequel a vu des flux, le flux vient chercher un obstacle, les obstacles passent les flux, le flux vient sur un obstacle, les flux rencontrent plus d'un obstacle, le flux va à la rencontre d'obstacles à rencontrer des flux, l'obstacle a plus d'un flux, l'obstacle passe dans le flux, un obstacle rencontre les flux, un flux et un obstacle se rencontrent ${ }^{26}$.

Aproximando Tarkos de Beckett ou Ghérasim, diríamos que há uma língua própria que se cria a partir de uma gagueira, para empregarmos a terminologia de Deleuze, de uma reiteração compulsiva. Língua esta que, no caso de Tarkos, se cria em uma associação de movimentos vocais com gestos tipicamente musicais, da improvisação pautada pelo som e pelo ritmo. É esta vivacidade do improviso que é sugerida na leitura dos textos de Tarkos, muitos dos quais nascidos efetivamente a partir de sua improvisação vocal ao microfone. A partitura que executamos ao ler é, portanto, bastante curiosa, pois vivenciamos a performance de uma improvisação - algo que, por definição, não possui uma partitura como base. É curiosa a sensação que esses poemas podem nos dar de estarem se escrevendo no momento mesmo em que lemos, como se assistíssemos a uma 
performance em que o próprio músico não sabe qual será o próximo som a ser executado. Estamos ambos, público e instrumentista - nós e o poema - imersos em um mesmo "tempo real”, um mesmo fluxo, presenciando juntos as imprevisibilidades que possam vir à tona dentre as palavras.

Esta imersão temporal é próxima à experiência encontrada em certas propostas do teatro contemporâneo, principalmente naquele que nasce na esteira de Beckett - tido por Hans-Thies Lehmann como um dos precursores do "teatro pós-dramático". Lehmann diz que esse novo teatro se definiria justamente por "uma radical afirmação do tempo real como situação vivenciada em comum” entre público, texto e atores ${ }^{27}$. Experiência em que o tempo da performance coincide com o tempo da representação. Já não se trata de acompanhar um tempo representado pela peça, um tempo da narrativa, mas sim de testemunhar no próprio corpo um tempo real, "ao vivo": tempo que acontece diante de nossos olhos e ouvidos. A linha do tempo narrativo é substituída por uma narrativa do próprio tempo da performance, tempo cênico, concreto, plástico, em que todos participam conjuntamente. Assim, a grande novidade dessas propostas pós-dramáticas, bem como das poéticas vocais das quais viemos falando, é a imersão rítmica à qual submetem o corpo de quem lê, escuta ou assiste. Imersão esta que se dá pela invasão do som na mudez do papel: a superfície aparentemente silenciosa da página foi invadida por vozes. Temas, significados, conceitos, nesta escrita imersiva, na proposta de partitura, não são mais algo que o texto representa, mas sim algo que se dá na performance do texto, nascendo conjunta e simultaneamente a ela.
27. LEHMANN, Hans-Thies. Teatro pós-dramático, 2007, p. 304. 


\section{Referências}

ANDRADE, Fábio de Souza. Samuel Beckett, o silêncio possível. São Paulo: Ateliê Editorial, 2001.

BECKETT, Samuel. Como é. Trad. Ana Helena Souza. São Paulo: Iluminuras, 2003 (dos originais em francês Comment c'est, 1961, e em inglês How is it, 1964).

O inominável. Trad. Ana Helena Souza. São Paulo: Globo, 2009 (do original L'Innommable, 1953).

BOBILLOT, Jean-Pierre. Bernard Heidsieck, poésie action. Paris: Jean Michel Place, 1996.

BOUCOURECHLIEV, Andé. Le Langage musical. Paris: Fayard, 1993.

BOULEZ, Pierre. Penser la Musique aujourd'hui. Paris: Gallimard, 1963.

CAGE, John. M. Middletown: Wesleyan University Press, 1974.

___. Silence. Middletown: Wesleyan University Press, 1973.

CAMPOS, Augusto de; PIGNATARI, Décio; CAMPOS, Haroldo de. Mallarmé. São Paulo: Perspectiva, 1974.

DELEUZE, Gilles. Critique et clinique. Paris: Minuit, 1993.

___; Guattari, Félix. Mille plateaux - Capitalisme et schizophrénie 2. Paris: Minuit, 1980.

HEIDSIECK, Bernard. Canal street. Paris: Al Dante, 2001.

LEHMANN, Hans-Thies. Teatro pós-dramático. Trad. Pedro Süssekind. São Paulo: Cosac Naify, 2007.

LUCA, Ghérasim. Héros-limite, suivi de La Chant de la carpe et de Paralipomènes. Paris: Gallimard/ Poche, 2001.

MESSIAEN, O. Techniques de mon langage musical. Paris: Leduc, 1940.

MURAT, Michel. Le Coup de dés de Mallarmé. Paris: Belin, 2005.

PAZ, Octavio. Signos em Rotação. Trad. Sebastião Uchoa Leite. São Paulo: Perspectiva, 1996. 
SARRAZAC, Jean-Pierre (org.). Léxico do drama moderno e contemporâneo. Trad. André Teles. São Paulo: Cosac Naify, 2012 (do original Lexique du drame moderne et contemporain, 2005).

TARKOS, Christophe. Caisses. Paris: P.O.L., 1998.

XENAKIS, Iannis. Musique et Architecture. Tournai:

Casterman, 1971.

ZUMTHOR, Paul. La Lettre et la voix. Paris: Seuil, 1987.

- Performance, recepção, leitura. Trad. Jerusa Pires

Ferreira e Suely Fenerich. São Paulo: Educ, 2000 (do original

Performance, réception, lecture, 1990). 
